\title{
BMJ Open Systematic review protocol: an assessment of the post-approval challenges of autologous CAR-T therapy delivery
}

Ching Lam, ${ }^{1}$ Edward Meinert, ${ }^{02,3}$ Celine-Lea Halioua-Haubold, ${ }^{2}$ Alison Carter, ${ }^{2}$ Aidong Yang, ${ }^{1}$ David Brindley, ${ }^{2}$ Zhanfeng Cui ${ }^{1}$

To cite: Lam C, Meinert E, Halioua-Haubold C-L, et al. Systematic review protocol: an assessment of the post-approval challenges of autologous CAR-T therapy delivery. BMJ Open 2019;9:e026172. doi:10.1136/ bmjopen-2018-026172

- Prepublication history and additional material is published online only. To view please visit the journal online (http://dx.doi. org/10.1136/bmjopen-2018026172).

Received 21 August 2018 Revised 22 February 2019 Accepted 5 June 2019

\section{Check for updates}

(C) Author(s) (or their employer(s)) 2019. Re-use permitted under CC BY-NC. No commercial re-use. See rights and permissions. Published by BMJ.

${ }^{1}$ Department of Engineering Sciences, University of Oxford, Oxford, UK

${ }^{2}$ Healthcare Translation Research Group, Department of Paediatrics, University of Oxford Oxford, UK

${ }^{3}$ Digital Global Health Unit, Department of Primary Care and Public Health, Imperial College London, London

Correspondence to EUR ING Dr Edward Meinert; e.meinert14@imperial.ac.uk, edward.meinert@paediatrics. ox.ac.uk

\section{ABSTRACT}

Introduction Following recent regulatory approvals of two chimeric antigen receptor T-cell (CAR-T) therapies, the field now faces a number of post-approval challenges. These challenges are in some respects defined and, in others, uncertain due to the nascence of the field. At present, information pertaining to such post-approval challenges are scattered in various previous reviews or raised in singular papers reporting experience in working with the therapy. This systematic review is designed to evaluate and summarise the post-approval challenges for robust delivery of CAR-T therapies to inform future work on the optimisation of CAR-T delivery to patients.

Methods and analysis We will search Medline, EMBASE (OvidSP), BIOSIS \& Web of Science, Cochrane Library, ICER database, NICE Evidence Search, CEA Registry, WHOLIS WHO Library and Scopus for studies published between 2014 and the present. In addition, a Google search for grey literature such as bioprocess blog posts, opinion pieces, press releases and listed companies involved in CAR-T development annual reports will be conducted. Two authors will independently screen the titles and abstracts identified from the search and accept or reject the studies according to the study inclusion criteria and any discrepancies will be discussed and resolved. The quality of the selected literature will be assessed using the Critical Appraisal Skills Programme(CASP) Systematic Review checklist and grey literature will be assessed using the Authority, Accuracy, Coverage, Objectivity, Date, Significance (AACODS) checklist. Data from eligible publications will be categorised using a flowchart and extracted using a data abstraction form. Qualitative and quantitative analysis of the post-approval challenges of CAR-T therapies will be conducted based on the results attained.

Ethics and dissemination The executed study will be published in a peer-reviewed journal in accordance with Preferred Reporting Items for Systematic Reviews and MetaAnalyses guidelines. The findings from this review will be used to inform the development of an optimisation model for robust delivery of CAR-T therapies using a systems engineering approach.

Trial registration number CRD42018109756.

\section{BACKGROUND}

Since the first reports of successes of using chimeric antigen receptor T-cell (CAR-T) to
Strengths and limitations of this study

- Only two approved products in 2017 make for relatively short-term and limited experiences with post-approval challenges.

- Annual reports of listed companies are not peer-reviewed but strictly regulated by relevant stock exchange.

- Only publicly listed companies that disclose their perceived risks are considered in this review hence there may be bias to larger companies' perspectives.

- Limiting to studies only of the English language may cause bias in the grey literature search. However, as both products have only been approved in Englishspeaking countries, the bias is relatively less significant.

treat advanced leukaemia in $2011,{ }^{12}$ the field has grown expansively with over 400 trials listed on ClinicalTrials.gov as of February 2018. The year 2017 saw the approvals of two of such therapies, Kymriah (Novartis, Basel, Switzerland) for the treatment of patients up to 25 years of age with B-cell relapsed/refractory acute lymphoblastic leukaemia (ALL) ${ }^{3}$ and Yescarta (Kite, acquired by Gilead) for treatment of adult patients with relapsed or refractory large B-cell lymphoma. ${ }^{4}$ The regulatory framework currently can allow rapid approval of CAR-T for niche indications through various acceleration schemes, but regulatory approval is at the beginning of another array of challenges facing companies.

In the case of Kymriah, the therapy was granted orphan designation, rare paediatric disease designation, fast track designation and breakthrough therapy designation which was awarded only around 1 month after initial submission. Figure 1 shows the development and regulatory timeline of Kymriah. Breakthrough therapy designation allowed biological licensing application (BLA) data to be 
DEVELOPMENT AND

APPROVAL TIMELINE OF KYMRIAH

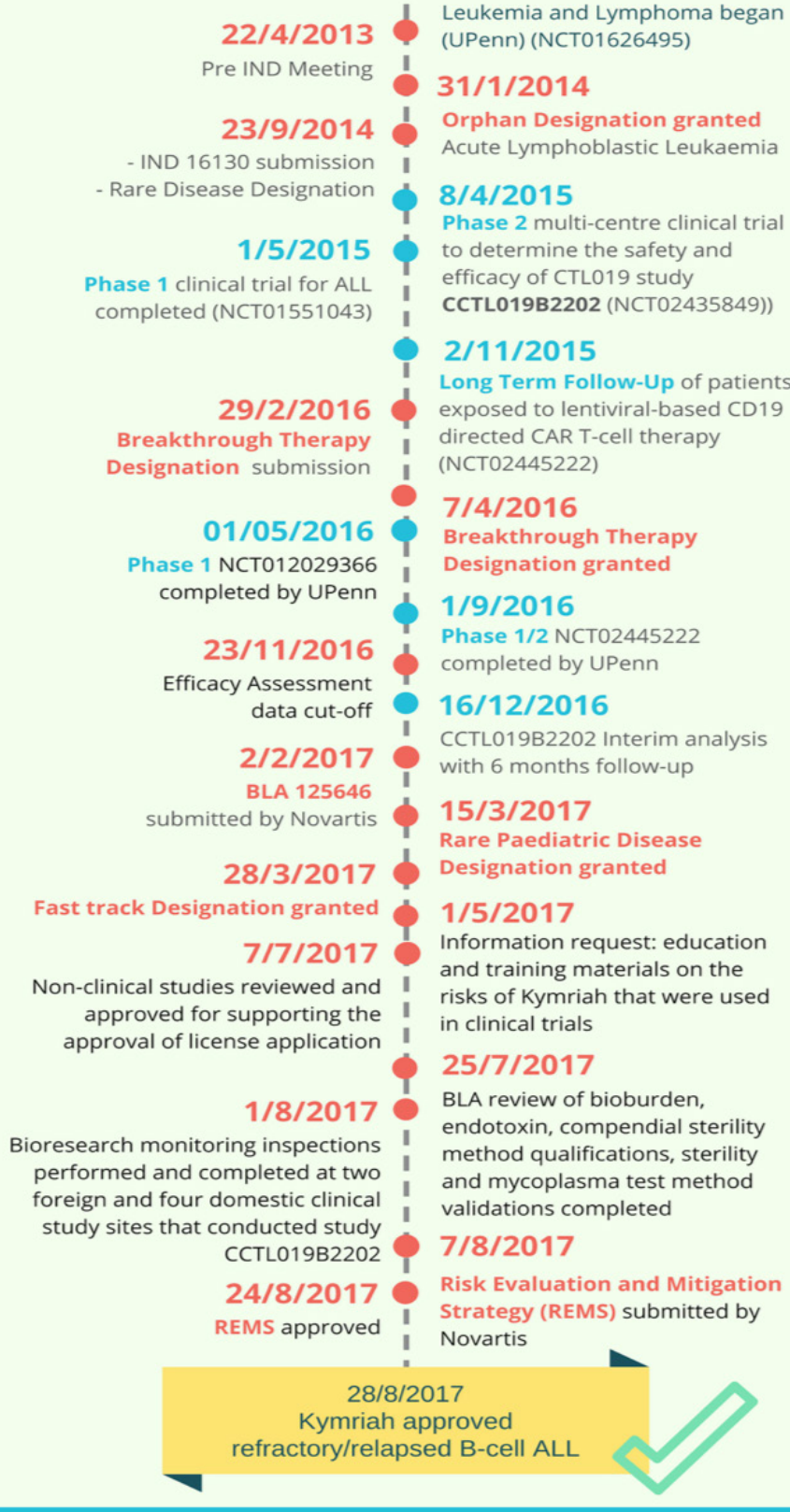

Figure 1 Development and approval timeline for Kymriah (in blue: clinical trial related milestones; in red: regulatory related milestones). ALL, acute lymphoblastic leukaemia; CAR, chimeric antigen receptor; UPenn, University of Pennsylvania.

submitted as it was accumulated, instead of in a single bolus on completion of pivotal clinical trials as part of a BLA as usually required by conventional Food and Drug Administration approval pathways and hence allow faster regulatory approval. In this case study, the regulatory process was accelerated from the conventional 10 month average from date of initial BLA submission to just 6 months.

With regulatory approval, there are still plenty of challenges that hinder patients from receiving these lifesaving treatments and companies from providing them in a robust manner. A retrospective review on commercialised cell therapy products conducted by Dodson ${ }^{5}$ categorised the translational challenges of cell therapies into pre-market, post-market and manufacturing challenges that start pre-market and continue into the post-market phase. Table 1 provides a summary of the challenges as mentioned in various previous reviews.

'Pre-market challenges' covers challenges incurred in preclinical and clinical research up until market approval. Various prior studies have looked into the clinical development of CAR-T. Liu et alsummarised the target antigen, indications, CAR and vectors chosen for registered clinical trials in China. ${ }^{6}$ While the study provides useful insights on the distribution and trends in CAR-T clinical trials in China, it did not critically appraise the safety and efficacy of CAR-T treatments nor did it address the state of development of the CAR-T industry. Pettitt et al systematically and qualitatively assessed the CAR-T clinical trial landscape, providing insights on the cell source and type, CAR, indication, number of participants, adverse events and outcomes, safety and efficacy of CAR-T treatments. ${ }^{7}$ Hartmann et al summarised the drivers in CAR-T clinical trial from target choice to administration and toxicity and efficacy as well as the regulatory hurdles associated to clinical translation of CAR-T cells. ${ }^{8}$ These reviews reiterate the clinical importance of CAR-T as an effective anti-cancer treatment mainly for haematological malignancies and reiterated the importance of post-approval surveillance for long-term safety and efficacy.

'Post-market challenges' include establishing reimbursement models and encouraging clinical adoption, ${ }^{5}$ as well as institutional challenges surrounding the delivery of the therapy ${ }^{9}$ and long-term safety. ${ }^{10}$ A quantitative review published recently conducted a multi-stakeholder and multi-national assessment focused on the barriers to the adoption of cell therapies, but not specific to CAR-T. ${ }^{11}$ Specific to CAR-T, Mcguirk $e t$ a ${ }^{9}$ discussed the institutional challenges from cell extraction (leukapheresis) to administration of the therapy and postoperative management and monitoring from their experience at the University of Kansas Medical Centre with Novartis' CTL019 (Kymriah). A well-trained multi-disciplinary team and associated infrastructure presents itself as a constraint to successful and timely delivery of CAR-T.

'Manufacturing challenges' for CAR-T therapies are very well researched and reviewed. ${ }^{12-14}$ Levine et $a l^{13}$ details the UPenn and Novartis approach to manufacturing of CAR-T. Vormittag et al ${ }^{12}$ reviewed the manufacturing technologies used in published clinical trials and summarised the commonly used equipment and manufacturing routes. Robust supply of all raw materials and consumables is important for the overall supply chain robustness. Brindley et $a l^{15}$ mentioned the limitation of 
Table 1 Table showing the challenges in the commercialisation of CAR-T therapies, table structure as adapted from Dodson

\begin{tabular}{|c|c|}
\hline Pre-market & Post-market \\
\hline 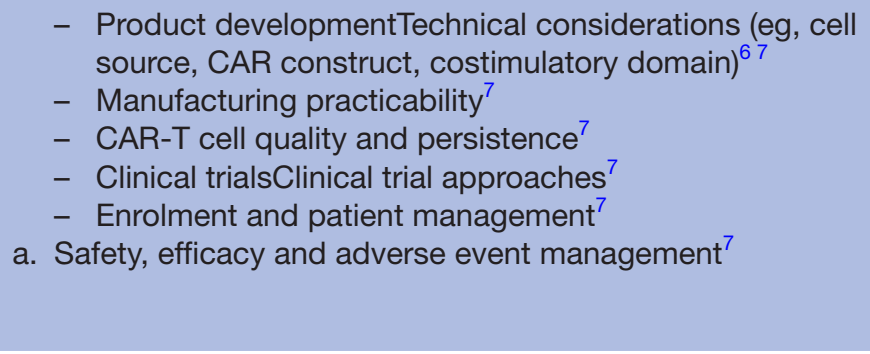 & $\begin{array}{l}\text { a. Long-term safety uncertainties }{ }^{10} \\
\text { - Institutional preparationTraining and education of care } \\
\text { team and patients }{ }^{9} \text { and clinical haematologists }{ }^{24} \\
\text { - Emergency department and intensive care unit }{ }^{9} \\
\text { - Side effects management }{ }^{9} \\
\text { b. Reimbursement }{ }^{1125} \\
\text { c. Clinical adoption }{ }^{11} \\
\text { d. Regulatory compliance, eg post-approval process } \\
\text { changes }^{26}\end{array}$ \\
\hline
\end{tabular}

\section{Manufacturing}

a. Manufacturing technologies ${ }^{12-14}$

b. Manufacturing models 2728

c. Supply chain

d. Raw material supply (eg, serum, ${ }^{15}$ viral vectors ${ }^{16}$ )

e. Capacity planning decisions (ie, partnership, in-house, outsource)

CAR-T, chimeric antigen receptor T-cell.

availability of serum in 2012 and viral vectors supplies are strained according to MacRae 2018. ${ }^{16}$

Public-private partnership and contracts signed for patents etc were reviewed by Bubela et al $2017^{17}$. The review was focused mostly on private-public partnerships, evaluating the collaborative research, technology licensing and some service agreements between companies and academic centres. However, as the products get commercialised, collaborations are slowly shifting towards company-to-company agreements for services such as contract manufacturing.

As products are getting past regulatory approval, more emphasis should be put on addressing post-approval challenges to allow for successful commercialisation. A comprehensive investigation into the challenges (eg, raw material supply pain points, supply chain, institutional challenges) for the delivery of autologous CAR-T can provide new insights into the overall process robustness from collection to post-administration of the therapy (ie, the process's ability to deliver successfully the therapy under varying conditions ${ }^{18}$ ).

\section{Objectives}

This systematic review aims to identify: (1) Key post-approval challenges of CAR-T therapies addressed in published literature and (2) Risks and concerns relating to delivery of CAR-T from the perspective of suppliers. These are critical in better understanding the constraints in the current delivery routine and identify the optimisation targets for future work on improving the robustness of delivery of CAR-T therapies through a systems engineering approach.

\section{Key research questions}

1. Primary research questions: What are the post-approval challenges for delivery of CAR-T therapies? What are the main concerns of CAR-T suppliers?
2. Secondary question: What has to be optimised and what are the constraints in robust delivery of CAR-T therapies?

\section{METHODS AND ANALYSIS}

This systematic review will be conducted following the Preferred Reporting Items for Systematic Reviews and Meta-Analyses (PRISMA) guidelines (online supplementary appendix 1$){ }^{19}$

\section{Eligibility criteria}

Table 2 shows the inclusion and exclusion criteria for this study. As the field is moving at a very fast pace, only English publications published within the last 5 years are included in this study. The earliest approval for CAR-T

\begin{tabular}{|lc}
\hline Table 2 Inclusion and exclusion criteria for the study \\
\hline Inclusion criteria & Exclusion criteria \\
\hline Published within the last & Non-English language \\
5years & publications \\
English language & Papers with exclusive \\
publications & focus on CAR-T basic \\
CAR-T related & research \\
Identified experiences & Clinical trials studies \\
in product supply chain, & Technical papers \\
delivery and clinical use & with exclusive focus \\
Identified challenges in & on bioprocess and \\
product supply chain, & manufacturing \\
delivery and clinical use & Papers that focus on pre- \\
& approval challenges such \\
& as regulatory approval \\
& hurdles \\
& Competing interests \\
& - sponsored by \\
& manufacturer
\end{tabular}

CAR-T, chimeric antigen receptor T-cell. 
Table 3 Themes and search term development

Search term/string: ((CAR-T) OR chimeric antigen receptor) AND+following

Theme keywords

$\begin{array}{ll}\text { Tissue procurement } & \begin{array}{l}\text { collection OR acquisition, } \\ \text { *apheresis, variability } \\ \text { Material acquisition }\end{array} \\ \text { Facility operation } & \begin{array}{l}\text { comparability } \\ \text { demand, scale, capacity, } \\ \text { outsourcing, *centralised }\end{array} \\ \text { Production } & \begin{array}{l}\text { GMP, schedul*, quality control, } \\ \text { personnel }\end{array} \\ \text { Distribution } & \begin{array}{l}\text { Packaging, distribution, logistics, } \\ \text { traceability } \\ \text { Institutional, long term safety, } \\ \text { Patient administration }\end{array}\end{array}$

is in August 2017, hence publications dating from long before this date are unlikely to be relevant. Only papers that look into post-approval commercialisation challenges - supply chain, delivery and clinical use - are included in order to omit irrelevant and generic challenges.

Early research papers on cellular level interactions and biology and clinical trials are considerations important for regulatory approval, hence irrelevant for post-approval challenges and hence excluded to ensure relevance.

Due to the nature of this study which looks at the post-approval challenges, a topic mostly discussed in industry and less so in academia, grey literature is an important source of the latest trends and updated information. To avoid bias in the grey literature search, sources sponsored by manufacturers and suppliers will be excluded.

\section{Search strategy}

The following databases will be searched, and publications published between 1 January 2014 to present will be assessed: Medline, EMBASE (OvidSP), BIOSIS \& Web of Science, Cochrane Library, ICER database, NICE Evidence Search, CEA Registry, WHOLIS WHO Library and Scopus. In addition, a Google search for grey literature such as bioprocess blog posts, opinion pieces, press releases and listed companies involved in CAR-T development annual reports will be conducted. Search terms in table 3 are developed around the CAR-T process from collection to delivery. The themes are designed according to the roadmap for cost-of-goods planning in cell therapy proposed by Lipsitz et al. ${ }^{20}$

In addition to the above search strings, to understand the post-marketing challenges of the two approved products that have been reported, the search as stipulated in table 4, which is limited to literature found between the approval date and present, will be conducted.

\section{Study selection}

Two independent reviewers will conduct the literature search according to this protocol. The manuscript title

\begin{tabular}{|c|c|}
\hline Product & Custom date range \\
\hline (Kymriah OR tisagenlecleucel) & 1 Sep 2017 - present \\
\hline $\begin{array}{l}\text { (Yescarta OR axicabtagene } \\
\text { ciloleucel) }\end{array}$ & 19 Oct 2017 - present \\
\hline
\end{tabular}

and abstracts will be screened, and eligibility determined independently by each reviewer. Valid studies will be assessed for their quality before any extraction of information. Any discrepancies that arise between the reviewers will be discussed until consensus is reached.

\section{Quality assessment and risk of bias}

Two reviewers will independently check each article to minimise bias using the Collaboration's risk of bias tool as described in the Cochrane Handbook for Systematic Review of Interventions. ${ }^{21}$ All selected articles will be judged for their quality based on the Critical Appraisal Skills Programme (CASP) systematic review checklist ${ }^{22}$ and the quality of any grey literature will be further assessed using the Authority, Accuracy, Coverage, Objectivity, Date, Significance (AACODS) checklist to grade the literature and ensure acceptable quality. ${ }^{23}$ The AACODS checklist was specifically designed by Tyndall for evaluation and critical appraisal of grey literature and due to the potential inclusion of grey literature produced by government, business and industry, the checklist is especially relevant for this systematic review.

\section{Data extraction}

Eligible sources will subsequently be reviewed in detail and key relevant challenges will be extracted and categorised into nine domains from the post-market and manufacturing challenges in table 1 :

1. Manufacturing (technologies and models).

2. Supply chain.

3. Raw material supply.

4. Capacity planning decisions.

5. Long-term safety uncertainties.

6. Institutional preparations.

7. Reimbursement.

8. Clinical adoption.

9. Regulatory compliance.

\section{Synthesis}

The identified challenges are then classified into (1) constraint, (2) optimisation target and (3) risk. Figure 2 shows the method of categorisation of the challenges identified and the data to extract if available. To provide some illustrative examples, shelf-life of the product can be identified as a constraint, and the product must be administered to patient within $x$ hours after formulation (range and limit); batch failure can be identified as a risk with $x \%$ risk of occurrence and consequence of batch loss; utilisation rate of resources such as personnel, equipment and cleanroom space can 


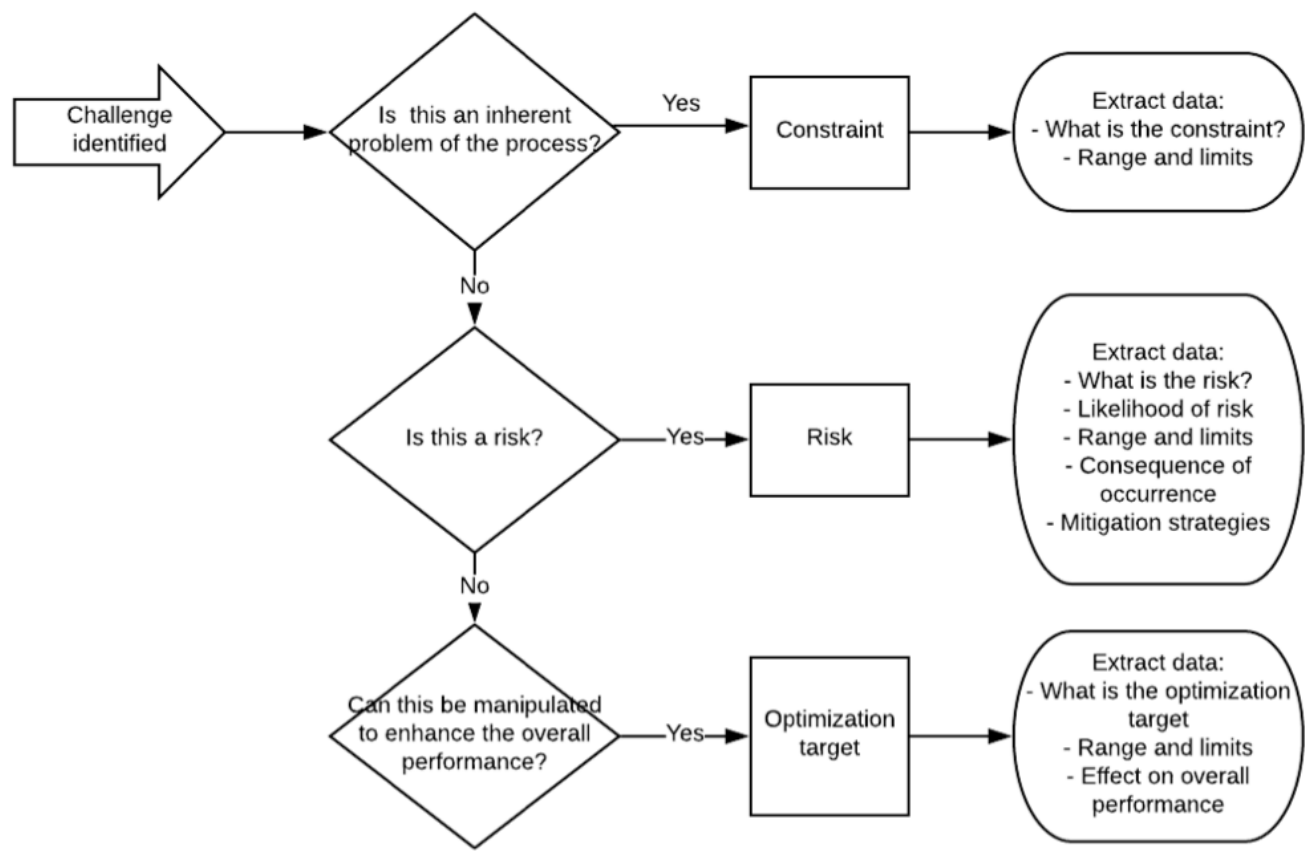

Figure 2 Schematic showing the categorisation and data extraction method.

be identified as a potential optimisation target to allow the overall system to become more resource-efficient.

The data will be categorised and extracted and recorded into a predesigned Excel database by each reviewer independently. Any discrepancies will be discussed until consensus is reached. This data will lay the basis for the formulation of a problem statement for future optimisation tools. Further to the data extraction, due to the heterogenous nature of the results from the preliminary analysis, a comprehensive review of the identified challenges will be qualitatively analysed to generate a narrative analysis of the post-approval challenges encountered by CAR-T commercialisation so far. If the results permit, a quantitative analysis will be conducted.

\section{Ethics and dissemination}

Due to the use of the publicly available, published data, this study will not require an ethical approval. The executed study conducted later in the year will be published in a peer-reviewed journal in accordance with PRISMA guidelines. Any deviations in the execution shall be noted in the subsequent systematic review publication. The findings from this review will be used to inform the development of an optimisation model for robust delivery of CAR-T therapies using a systems engineering approach.

Acknowledgements David Williams and Brock Reeve provided review and commentary on the paper themes. We would also like to thank the Bodleian Radcliffe Science Library librarian, Alessandra Vetrugno and Bodleian Health Care Library librarian, Nia Roberts for their guidance in reviewing the search strategy proposed in this protocol.

Contributors CL conceptualised and wrote the manuscript. EM provided systematic review expertise and assisted in the development of the protocol methodology. AY provided valuable systems engineering expertise for the development of the methods and amendments for clarity. CLHH, DAB, ARC and ZFC edited for relevance and clarity and are the senior guarantying authors. All authors approved the final manuscript. All authors read and approved the final manuscript. All authors completed the ICMJE uniform disclosure form at www.icmje.org/coi disclosure.pdf. There are no relevant conflicts of interest, financial or other types of relationships that may influence the manuscript declared by authors. Authors do not have any patents and are not associated to any conditions or circumstances that may lead to conflicts of interest.

Funding $\mathrm{CL}$ is funded by the CRMI-0xford Technology Centre Studentship. CLHH is supported by the SENS Research Foundation \& Centre for Advancement of Sustainable Medicines (SRF-CASMI) Alliance to CLHH. EM is supported by the Sir David Cooksey Fellowship at the University of Oxford. DB gratefully acknowledges personal funding from the Oxford National Institute for Health Research Biomedical Research Centre (BRC). DB is additionally supported by the Saïd Foundation and the SENS Research Foundation.

Competing interests None declared.

Patient consent for publication Not required.

Provenance and peer review Not commissioned; externally peer reviewed.

Open access This is an open access article distributed in accordance with the Creative Commons Attribution Non Commercial (CC BY-NC 4.0) license, which permits others to distribute, remix, adapt, build upon this work non-commercially, and license their derivative works on different terms, provided the original work is properly cited, appropriate credit is given, any changes made indicated, and the use is non-commercial. See: http://creativecommons.org/licenses/by-nc/4.0/.

\section{REFERENCES}

1. Kalos M, Levine BL, Porter DL, et al. T cells with chimeric antigen receptors have potent antitumor effects and can establish memory in patients with advanced leukemia. Sci Trans/ Med 2011;3:95ra73.

2. Porter DL, Levine BL, Kalos M, et al. Chimeric antigen receptormodified T cells in chronic lymphoid leukemia. $N$ Engl J Med 2011;365:725-33.

3. Novartis. Novartis receives first ever FDA approval for a CAR-T cell therapy, Kymriah(TM) (CTL019), for children and young adults with B-cell ALL that is refractory or has relapsed at least twice | Novartis. 2017. Available at https://www.novartis.com/news/mediareleases/novartis-receives-first-ever-fda-approval-car-t-cell-therapykymriahtm-ctl019 (Accessed 2 Apr 2018).

4. Gilead. Kite's YescartaTM (Axicabtagene Ciloleucel) Becomes First CAR T Therapy Approved by the FDA for the Treatment of Adult Patients With Relapsed or Refractory Large B-Cell Lymphoma After Two or More Lines of Systemic Therapy. 2017:1-6. 
5. Dodson BP, Levine AD. Challenges in the translation and commercialization of cell therapies. BMC Biotechnol 2015;15:70.

6. Liu B, Song Y, Liu D. Clinical trials of CAR-T cells in China. J Hematol Oncol 2017:10:1-10.

7. Pettitt D, Arshad Z, Smith J, et al. CAR-T Cells: A Systematic Review and Mixed Methods Analysis of the Clinical Trial Landscape. Mol Ther 2018;26:342-53.

8. Hartmann J, Schüßler-Lenz M, Bondanza A, et al. Clinical development of CAR T cells - challenges and opportunities in translating innovative treatment concepts. EMBO Mol. Med 2017;9:e201607485.

9. Mcguirk J, et al. Building blocks for institutional preparation of CTL019 delivery. 2017.

10. Zheng PP, Kros JM, Li J. Approved CAR T cell therapies: ice bucket challenges on glaring safety risks and long-term impacts. Drug Discov Today 2018;23.

11. Davies BM, Smith J, Rikabi S, et al. A quantitative, multi-national and multi-stakeholder assessment of barriers to the adoption of cell therapies. J Tissue Eng 2017;8:204173141772441.

12. Vormittag P, Gunn R, Ghorashian S. \& Veraitch, F. S. A guide to manufacturing CAR T cell therapies. Curr. Opin. Biotechnol 2018;53:164-81.

13. Levine BL, Miskin J, Wonnacott K, et al. Global Manufacturing of CAR T Cell Therapy. Mol Ther Methods Clin Dev 2017;4:92-101.

14. Kaiser AD, Assenmacher M, Schröder B, et al. Towards a commercia process for the manufacture of genetically modified $\mathrm{T}$ cells for therapy. Cancer Gene Ther 2015;22:72-8.

15. Brindley DA, Davie NL, Culme-Seymour EJ, et al. Peak serum: implications of serum supply for cell therapy manufacturing. Regen Med 2012;7:7-13.

16. MacRae M. Virus Shortage for Cell Therapies Creates Engineering Opp. 2018. Available at https://aabme.asme.org/posts/virusshortage-for-cell-therapies-creates-engineering-opportunity (Accessed 2 Apr 2018).
17. Bubela T, Bonter K, Lachance S, et al. More Haste, Less Speed: Could Public-Private Partnerships Advance Cellular Immunotherapies? Front Med 2017;4:134.

18. Vieira GE, Lemos $R$. Understanding supply chain robustness. 2009 IEEE/INFORMS Int Conf Serv Oper Logist Informatics, SOLI 2009:157-62.

19. Liberati A, Altman DG, Tetzlaff J, et al. The PRISMA statement for reporting systematic reviews and meta-analyses of studies that evaluate health care interventions: explanation and elaboration. PLoS Med 2009;6.

20. Lipsitz YY, Milligan WD, Fitzpatrick I, et al. A roadmap for costof-goods planning to guide economic production of cell therapy products. Cytotherapy 2017;19.

21. Higgins JP, Altman DG, Gøtzsche PC, et al. The Cochrane Collaboration's tool for assessing risk of bias in randomised trials. BMJ 2011;343:d5928.

22. Critical Appraisal Skills Program. CASP Systematical Review Checklist. (2018)

23. Tyndall J. AACODS Checklist. 2010.

24. Lowdell MW, Thomas A. The expanding role of the clinical haematologist in the new world of advanced therapy medicinal products. Br J Haematol 2017;176:9-15.

25. Malik NN, Durdy MB. Commercialisation of CAR T-cell therapies: business model spectrum. Drug Discov Today 2017;22:1-4.

26. Williams DJ, Archer R, Archibald P, et al. Comparability: manufacturing, characterization and controls, report of a UK Regenerative Medicine Platform Pluripotent Stem Cell Platform Workshop, Trinity Hall, Cambridge, 14-15 September 2015. Regen Med 2016;11:483-92.

27. Harrison RP, Ruck S, Medcalf N, et al. Decentralized manufacturing of cell and gene therapies: Overcoming challenges and identifying opportunities. Cytotherapy 2017;19:1140-51.

28. Medcalf N. Centralized or decentralized manufacturing ? Key business model considerations for cell therapies. Cell Gene Ther Insights 2016;2:95-109. 